\title{
Aqueous production of spherical Zr-MOF beads via
}

\section{continuous-flow spray-drying}

Ceren Avci-Camur, ${ }^{\dagger}$ Javier Perez-Carvajal,,$^{\dagger}$ Inhar Imaz, ${ }^{* \dagger}$ and Daniel Maspoch ${ }^{*}+\neq$

$\dagger \quad$ Catalan Institute of Nanoscience and Nanotechnology (ICN2), CSIC and The Barcelona Institute of Science and Technology, Campus UAB, Bellaterra, 08193 Barcelona, Spain. E-mail: inhar.imaz@icn2.cat, daniel.maspoch@icn2.cat

$\$ \quad$ ICREA, Pg. Lluís Companys 23, 08010 Barcelona, Spain

KEYWORDS: Metal-organic frameworks, Green synthesis, Water

\begin{abstract}
Porous metal-organic frameworks (MOFs) are attracting great attention from industry, thanks to their myriad potential applications in areas such as catalysis and gas storage. Zr-MOFs (also known as UiO-type MOFs) are especially promising, owing to their large surface areas, high chemical versatility and remarkable hydrothermal, chemical and thermal stability. However, among the challenges currently precluding the industrial exploitation of MOFs is the lack of green methods for their synthesis. Herein we describe a continuous-flow spray-drying method for the simultaneous synthesis and shaping of spherical MOF microbeads in a mixture of water and acetic
\end{abstract}


This is the accepted version of the article: Avci-Camur, C., Troyano, J., Pérez-Carvajal, J., Legrand, A., Farrusseng, D., Imaz, I., Maspoch, D. Aqueous production of spherical Zr-MOF beads: Via continuous-flow spray-drying, Green Chemistry, 20(4):2018, p. 873-878. Available at: https:// doi.org/10.1039/c7gc03132g. All rights reserved

acid. We used this approach to build two archetypical Zr-MOFs: UiO-66-NH2 and Zr-fumarate. By tuning the concentration of acetic acid in water, we were able to produce, by a scalable process, UiO-66-NH2 and Zr-fumarate beads with SBET and water-sorption values comparable to literature values obtained with other methods.

\section{INTRODUCTION}

Metal-organic frameworks (MOFs) are an emerging class of porous materials with industrial relevance in many fields, including gas storage and separation, $1-3$ catalysis, 4,5 adsorption heat transformations (AHT),6-9 and contaminant sequestration.10,11 However, industry and academic experts widely agree that effective exploitation and commercialisation of MOFs depend on the development of scalable, sustainable and cost-effective fabrication processes.12-16 Ideally, such green processes should enable continuous manufacturing MOFs from non-toxic reagents in an energy-efficient way. Additionally, they should be specific for each targeted MOF, as small variations in process parameters can have structural and functional (e.g. stability, adsorption, etc.) consequences. $17-19$

Green methods for MOF synthesis should be aqueous, as water is safer and cheaper than using organic solvents. However, this is not trivial, as most organic linkers are poorly soluble in water and most MOFs are not stable in water.20-22 This drawback is even more pronounced for continuous-fabrication methods, whereby the reaction time between organic linkers and metal ions is significantly lower than in batch methods. However, to date, major advances have been made in the aqueous synthesis of MOFs using continuous-flow chemistry. In these methods, watersolubility issues have been mitigated mainly by using sodium salts of the organic linkers and by increasing the length of the tubing systems to increase the reaction time. For example, Schröder 
This is the accepted version of the article: Avci-Camur, C., Troyano, J., Pérez-Carvajal, J., Legrand, A., Farrusseng, D., Imaz, I., Maspoch, D. Aqueous production of spherical Zr-MOF beads: Via continuous-flow spray-drying, Green Chemistry, 20(4):2018, p. 873-878. Available at: https:// doi.org/10.1039/c7gc03132g. All rights reserved

and Poliakoff et al. reported a continuous-flow aqueous synthesis of MIL-53-Al (SBET = 1010 $\mathrm{m} 2 \mathrm{~g}-1)$ based on reaction of $\mathrm{Al}(\mathrm{NO} 3) 3 \cdot 9 \mathrm{H} 2 \mathrm{O}$ with sodium terephthalate for $10 \mathrm{~min}$ at $250{ }^{\circ} \mathrm{C} .23$ Similarly, Blom et al. showed that CPO-27-Ni (SBET = $1085 \mathrm{~m} 2 \mathrm{~g}-1)$ could be synthesised in water by reacting $\mathrm{Ni}(\mathrm{OAc}) 2 \cdot 2 \mathrm{H} 2 \mathrm{O}$ with sodium 2,5 -dihydroxyterephthalate for $20 \mathrm{~min}$ at $90{ }^{\circ} \mathrm{C} .24$ As well, Stock et al. produced UiO-66-NH2 $(\mathrm{SBET}=1150 \mathrm{~m} 2 \mathrm{~g}-1)$ by reacting $\mathrm{ZrOCl} 2 \cdot 8 \mathrm{H} 2 \mathrm{O}$ and 2-aminoterephthalic acid and $\mathrm{Zr}$-fumarate $(\mathrm{SBET}=1200 \mathrm{~m} 2 \mathrm{~g}-1)$ by reacting $\mathrm{ZrOCl} 2 \cdot 8 \mathrm{H} 2 \mathrm{O}$ with fumaric acid for $22 \mathrm{~min}$ at $85^{\circ} \mathrm{C}$ in the presence of acetic acid.25 Interestingly, Lester et al. recently demonstrated large-scale aqueous fabrication of ZIF-8 (810 g h-1) by reacting $\mathrm{Zn}(\mathrm{OAc}) 2 \cdot 2 \mathrm{H} 2 \mathrm{O}$ and 2-methylimidazole with a base for $5 \mathrm{~min}$ in a pilot-scale, continuous countercurrent reactor. 26

Another approach to continuous fabrication of MOFs is spray-drying,27-30 a mature technology that has been widely deployed in many industrial sectors. Existing lab-scale spray-drying processes can easily be scaled-up to pilot scale, including for tonne-scale production. Briefly, this technique entails the transformation of a liquid stream (solution, suspension or emulsion) into a dried powder upon rapid evaporation of the solvent using a hot gas. In 2013 we demonstrated that, when the liquid stream contains metal ions and organic linkers, spray-drying can also be used to simultaneously synthesise and shape MOFs in the form of hollow or compact microscale spheres or beads.28, 29, 31 More recently, we showed that high-nuclearity MOF (e.g. UiO-type family) beads can also be produced by employing a continuous-flow process at the entrance to the spraydrier.29 However, to date, all spray-drying syntheses of MOFs have involved organic solvents such as $\mathrm{N}, \mathrm{N}^{\prime}$-dimethylformamide (DMF).32-35

Zr-type MOFs are characterised by their large surface areas, chemical versatility and remarkably high hydrothermal, chemical and thermal stability, making them promising for catalysis, gas and 
This is the accepted version of the article: Avci-Camur, C., Troyano, J., Pérez-Carvajal, J., Legrand, A., Farrusseng, D., Imaz, I., Maspoch, D. Aqueous production of spherical Zr-MOF beads: Via continuous-flow spray-drying, Green Chemistry, 20(4):2018, p. 873-878. Available at: https:// doi.org/10.1039/c7gc03132g. All rights reserved

pollutant capture and adsorption, heat transformation and separation processes.31, 36-38 Synthesis of this MOF family can be improved through the use of acids. Moreover, acetic acid can also be incorporated into UiO-type structures, leading to networks that contain missing-linker defects and that usually exhibit higher uptake capacities.18, 39

Here, we demonstrate the utility of continuous-flow spray-drying for aqueous fabrication and shaping of spherical Zr-MOF microbeads. This rapid technique uses reaction times of only 60 to 90 seconds. The ability to synthesise and shape MOFs in a single step is important for industrial applications, most of which demand specific shapes (e.g. tablets, extrudates, granulates or monoliths).40-43 As proof of concept, we prepared two water-stable members of the UiO-type family: UiO-66-NH2 and Zr-fumarate (also known as MOF-801). We then evaluated the BET surface areas (SBET) from N2 sorption and the water sorption properties of these beads.

\section{RESULTS AND DISCUSSION}

\section{Aqueous synthesis of UiO-66-NH2 beads}

A schematic illustration of the aqueous continuous-flow spray-drying set-up is shown in Fig. 1. In a typical synthesis, an equimolar mixture of $\mathrm{ZrOCl} 2 \cdot 8 \mathrm{H} 2 \mathrm{O}$ and 2 -aminoterephthalic acid (BDC$\mathrm{NH} 2$ ) in a mixture of water and acetic acid was injected into a coil-flow reactor (i.d: $3 \mathrm{~mm}$ ), which was placed into a silicone bath. The reaction was run using a specific coil-flow reactor temperature $\left(\mathrm{Tc}\right.$; in $\left.{ }^{\circ} \mathrm{C}\right)$ and liquid-feed rate (Qlf; in $\mathrm{mL}$ min-1). The resulting yellow slurry was then spraydried at a specific inlet temperature (Tin; in ${ }^{\circ} \mathrm{C}$ ) and drying-gas $(\mathrm{N} 2)$ flow rate (Qdg; in $\mathrm{mL}$ min1) using a B-290 Mini Spray Dryer (BUCHI Labortechnik). The beads were collected, washed with ethanol and acetone, and then dried at $75^{\circ} \mathrm{C}$ in air. 
This is the accepted version of the article: Avci-Camur, C., Troyano, J., Pérez-Carvajal, J., Legrand, A., Farrusseng, D., Imaz, I., Maspoch, D. Aqueous production of spherical Zr-MOF beads: Via continuous-flow spray-drying, Green Chemistry, 20(4):2018, p. 873-878. Available at: https:// doi.org/10.1039/c7gc03132g. All rights reserved

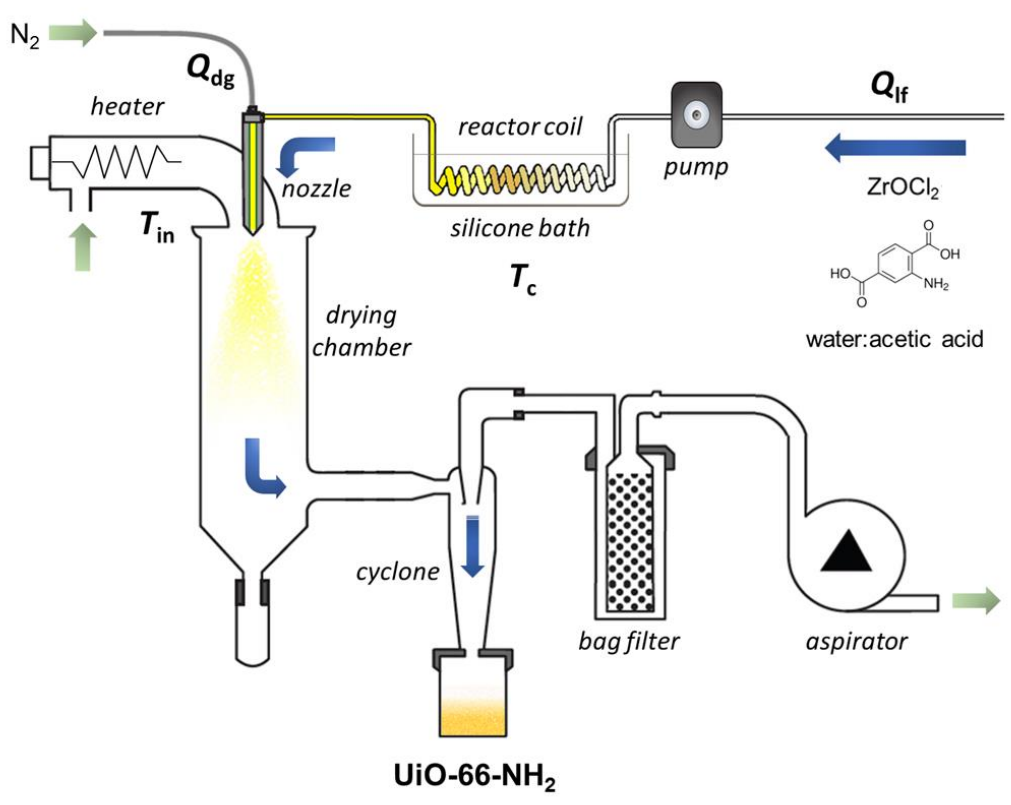

Figure 1. Schematic illustration of the set-up for the aqueous continuous-flow spray-drying synthesis of UiO-66-NH2.

In addition to optimisation of standard synthetic parameters (e.g. stoichiometry), our continuousflow spray-drying method also demands evaluation of Tc, Tin, Qlf and Qdg. Using this method, we initially produced UiO-66-NH2 beads using a $0.05 \mathrm{M}$ solution of $\mathrm{ZrOCl} 2 \cdot 8 \mathrm{H} 2 \mathrm{O}$ and a $1: 1$ stoichiometric ratio of $\mathrm{ZrOCl} 2 \cdot 8 \mathrm{H} 2 \mathrm{O}$ and $\mathrm{BDC}-\mathrm{NH} 2$. The total molar ratio of $\mathrm{Zr} / \mathrm{BDC}-\mathrm{NH} 2 /$ acetic acid was defined as 1:1:50, which corresponds to an acetic acid concentration of $14 \%(\mathrm{v} / \mathrm{v})$ in water. The optimal Tc was found to be $90{ }^{\circ} \mathrm{C}$, as using lower values led to UiO-66-NH2 with smaller SBET values (Table S1, ESI $\dagger$ ). The optimal Qlf was defined as $2.4 \mathrm{~mL}$ min-1, as higher values led to incomplete drying of the droplets. The residence time inside the coil-flow reactor was $63 \mathrm{~s}$. As an additional green measure, we sought to minimise Tin, as this would translate to lower energy use and cost. Thus, Tin was set to $150^{\circ} \mathrm{C}$, which was the lowest temperature at which the solvent fully evaporated inside the spray-dryer. Finally, a Qdg of $336 \mathrm{~mL} \mathrm{~min}-1$ was used, based 
This is the accepted version of the article: Avci-Camur, C., Troyano, J., Pérez-Carvajal, J., Legrand, A., Farrusseng, D., Imaz, I., Maspoch, D. Aqueous production of spherical Zr-MOF beads: Via continuous-flow spray-drying, Green Chemistry, 20(4):2018, p. 873-878. Available at: https:// doi.org/10.1039/c7gc03132g. All rights reserved

on earlier findings that it enables optimal nebulisation for MOF synthesis.28,29 The resulting yellow powder (yield: 70\%) was characterised by X-ray powder diffraction (XRPD), which confirmed the formation of crystalline UiO-66-NH2 (Fig. S1a, ESI $\dagger$ ). The microporosity of this sample was analysed by N2 adsorption measurements at $77 \mathrm{~K}$ (Fig. S1b, ESI $\dagger$ ), giving an estimated BET surface area (SBET) of $840 \mathrm{~m} 2 \mathrm{~g}-1$. This SBET value is within the range reported for UiO66-NH2 synthesised in DMF.29, 44, 45

To explore the synergic effects of coupling spray-drying to continuous-flow, we synthesised UiO-66-NH2 using each of these techniques separately. Spray-drying alone provided a non-porous amorphous product, whereas continuous-flow synthesis alone afforded UiO-66-NH2 as a crystalline solid but in a much lower yield (6\%) than that obtained with the coupled method.

Having successfully produced UiO-66-NH2 by continuous-flow spray-drying, we then sought to increase the yield by optimising the reagent concentrations. There are two main factors that limit the usable amounts of reagents in this reaction: the solubility of the organic ligand in water; and the blockage of the reaction coil during synthesis, due to accumulation of precipitates. The maximum useable concentration of $\mathrm{ZrOCl} 2 \cdot 8 \mathrm{H} 2 \mathrm{O}$ and $\mathrm{BDC}-\mathrm{NH} 2$ that we identified was $0.2 \mathrm{M}$ for each reagent (Table S2, ESI $\dagger$ ). Since the total molar ratio of $\mathrm{Zr} / \mathrm{BDC}-\mathrm{NH} 2 /$ acetic acid was kept at 1:1:50, the concentration of acetic acid in water was $56 \%(\mathrm{v} / \mathrm{v})$. These conditions afforded compact spherical UiO-66-NH2 beads (size: 2-12 $\square \mathrm{m}$ ) in high yield (72\%) and with a larger SBET (1036 $\mathrm{m} 2 \mathrm{~g}-1)$ than that obtained previously (Fig. 2). Thermogravimetric analysis (TGA) revealed that these UiO-66-NH2 beads are stable up to near $400{ }^{\circ} \mathrm{C}$, as depicted in Fig. S2 (ESI $\dagger$ ). 
This is the accepted version of the article: Avci-Camur, C., Troyano, J., Pérez-Carvajal, J., Legrand, A., Farrusseng, D., Imaz, I., Maspoch, D. Aqueous production of spherical Zr-MOF beads: Via continuous-flow spray-drying, Green Chemistry, 20(4):2018, p. 873-878. Available at: https:// doi.org/10.1039/c7gc03132g. All rights reserved

a)

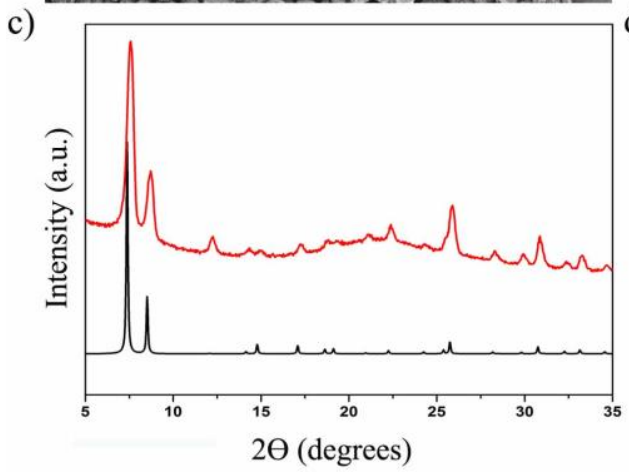

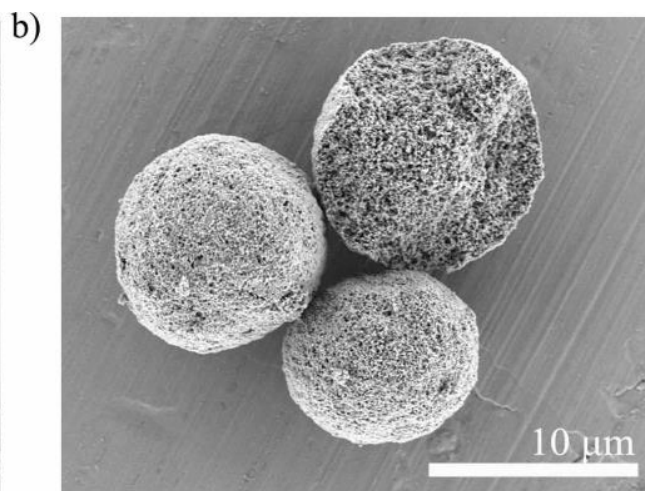

d)

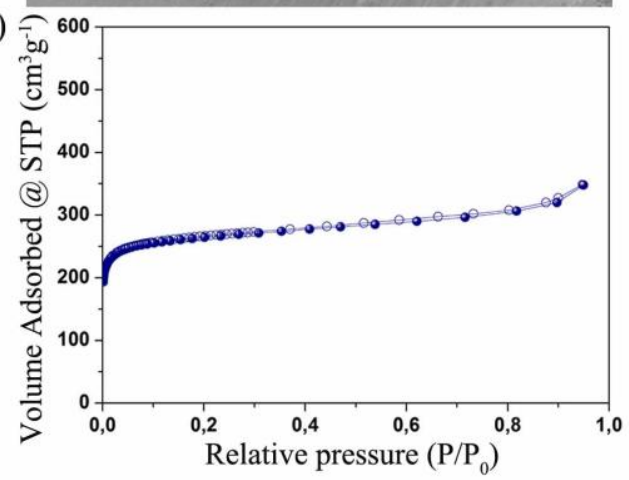

Figure 2. Characterisation of UiO-66-NH2 produced under optimised synthetic conditions $([\mathrm{Zr}]=$ $0.2 \mathrm{M} ; 3.2 \mathrm{~mL}$ of acetic acid $\left(56 \% \mathrm{v} / \mathrm{v}\right.$ in water); $\left.\mathrm{Q} 1 \mathrm{f}=2.4 \mathrm{~mL} \min -1 ; \mathrm{Tc}=90{ }^{0} \mathrm{C}\right) .(\mathrm{a}, \mathrm{b})$ Representative FESEM images showing the compact microspherical beads of UiO-66-NH2. (c) XRPD diffractogram (red) compared to the simulated powder pattern for UiO-66 (black). (d) N2 adsorption (filled dots) desorption (empty dots) isotherm at $77 \mathrm{~K}$.

\section{Modulator effects on the synthesis of UiO-66- $\mathrm{NH}_{2}$ beads}

We attributed the gain in $\mathrm{S}_{\mathrm{BET}}$ value in the synthesised UiO-66-NH2 beads to the increased concentration of acetic acid. Given that addition of acids (e.g. hydrochloric or acetic acid) can improve the formation and the crystallinity of UiO-type materials46-48 and that they can be incorporated in the structures leading usually to higher uptake capacities, 18,43 we reasoned that this effect could depend on concentration. Thus, we studied the influence of the modulator in the continuous-flow spray-drying synthesis of $\mathrm{UiO}-66-\mathrm{NH}_{2}$ beads by systematically increasing the 
This is the accepted version of the article: Avci-Camur, C., Troyano, J., Pérez-Carvajal, J., Legrand, A., Farrusseng, D., Imaz, I., Maspoch, D. Aqueous production of spherical Zr-MOF beads: Via continuous-flow spray-drying, Green Chemistry, 20(4):2018, p. 873-878. Available at: https:// doi.org/10.1039/c7gc03132g. All rights reserved

concentration of acetic acid from 10\% to $70 \%(\mathrm{v} / \mathrm{v})$ under the optimised synthetic conditions (vide supra). To assess the reproducibility of the chemistry, each concentration was tested in triplicate. The resulting powders were characterised by FESEM, which revealed the formation of microscale structures ranging in shape from donut-like (at acetic acid concentrations $[\mathrm{v} / \mathrm{v}]$ of $10 \%$ and $20 \%$ ) to a more spherical shape (at concentrations $\geq 30 \%$; Fig. S3, ESI†). XRPD confirmed that all these powders were crystalline UiO-66-NH2 (Fig. 3a). However, UiO-66-NH2 beads synthesised using acetic acid at concentrations from $30 \%$ to $60 \%$ exhibited better crystallinity, as evidenced by the calculated full width at half maximum (FWHM) values and average crystallite sizes (Table S3, ESI††). Remarkably, a similar trend had already been reported in the modulated hydrothermal batch synthesis of Zr-MOFs,49,50 whereby crystallinity was optimised by increasing the modulator up to a certain point, above which was observed a loss in crystallinity. For these more crystalline samples, the molar ratio of acetate/BDC-NH2 in the structure determined by $1 \mathrm{H}-\mathrm{NMR}$ ranged from 0.03 to 0.13 , values that agree with those reported in the literature for samples of UiO-66 synthesised in the presence of acids at high temperatures (Fig. S4 and S5, ESI $†$ ).51 
This is the accepted version of the article: Avci-Camur, C., Troyano, J., Pérez-Carvajal, J., Legrand, A., Farrusseng, D., Imaz, I., Maspoch, D. Aqueous production of spherical Zr-MOF beads: Via continuous-flow spray-drying, Green Chemistry, 20(4):2018, p. 873-878. Available at: https:// doi.org/10.1039/c7gc03132g. All rights reserved
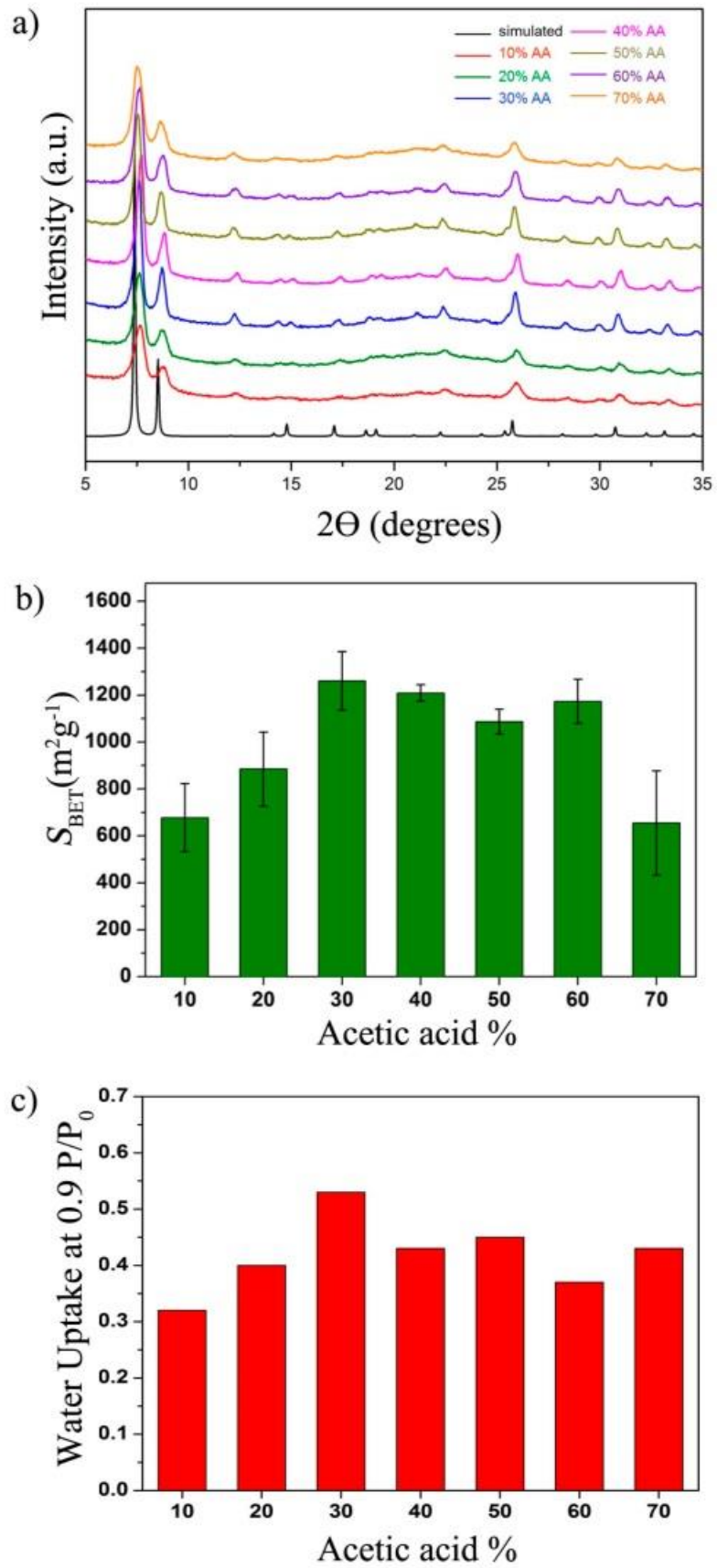

Figure 3. (a) XRPD diffractograms of UiO-66-NH2 synthesised using different concentrations of acetic acid (v/v, in water) compared to the simulated powder pattern for UiO-66 (black). (b,c) SBET values (b) and maximum water uptake values (c) for UiO-66-NH2 samples prepared using different concentrations of acetic acid. 
This is the accepted version of the article: Avci-Camur, C., Troyano, J., Pérez-Carvajal, J., Legrand, A., Farrusseng, D., Imaz, I., Maspoch, D. Aqueous production of spherical Zr-MOF beads: Via continuous-flow spray-drying, Green Chemistry, 20(4):2018, p. 873-878. Available at: https:// doi.org/10.1039/c7gc03132g. All rights reserved

We measured the N2 adsorption isotherms on all synthesised UiO-66-NH2 (Fig. S6-12, ESI†). We found that, when using acetic acid at concentrations from $30 \%$ to $60 \%$, the synthesised UiO-66NH2 beads exhibited the greatest mean values for SBET (Fig. 3b), consistent with their greater crystallinity. In this range, the maximum mean SBET was $1261 \mathrm{~m} 2 \mathrm{~g}-1$ at an acetic acid concentration of $30 \%$, which is within the range reported for UiO-66-NH2 samples synthesised in DMF or water using acids such as $\mathrm{HCl} .25,52$ Likewise, the water sorption isotherms revealed this range of acetic acid concentrations provided the greatest water uptake, with the highest value $(0.57$ gwater g-1) seen also at an acetic acid concentration of $30 \%$, as well as the expected S-type trend, centred at $0.2 \mathrm{P} / \mathrm{P} 0$ (Fig. 3c, Fig. S13, ESI†).53

\section{Modulated aqueous synthesis of Zr-fumarate beads}

Encouraged by our results, we extended our aqueous continuous-flow spray-drying method to the synthesis of Zr-fumarate beads.38,54 We followed a synthetic protocol analogous to that which we had earlier used for UiO-66-NH2, and studied the influence of the concentration of acetic acid on the production of Zr-fumarate beads. In this case, acetic acid concentration values of $10 \%$ and $60 \%$ both led to quasi-amorphous materials (Fig. 4a). However, concentrations from $20 \%$ to $50 \%$ provided Zr-fumarate, as evidenced by XRPD (Fig. 4a). Here, FESEM revealed the formation of micron-sized spherical beads comprising nanoparticles of Zr-fumarate (Fig. 4b and Fig. S14, ESI $\dagger$ ). In this range, an acetic acid concentration of 30\% provided optimal crystallinity (Table S4, ESI $\dagger$ ). All synthesised samples contained an acetate/fumarate molar ratio between 0.2-0.3, which perfectly agrees with those previously reported for this MOF (Fig. S15, ESI† ).50 
This is the accepted version of the article: Avci-Camur, C., Troyano, J., Pérez-Carvajal, J., Legrand, A., Farrusseng, D., Imaz, I., Maspoch, D. Aqueous production of spherical Zr-MOF beads: Via continuous-flow spray-drying, Green Chemistry, 20(4):2018, p. 873-878. Available at: https:// doi.org/10.1039/c7gc03132g. All rights reserved

The N2 and water sorption isotherms showed that the quality of the synthesised Zr-fumarate beads correlated to their crystallinity (Fig. S16-20, ESI†). In fact, the maximum mean SBET value (664 $\mathrm{m} 2 \mathrm{~g}-1$ ) was obtained at an acetic acid concentration of $30 \%$ (Fig. 4c). This value was comparable to that previously reported for a water-batch synthesis, 50 but lower than those reported for an aqueous continuous-flow synthesis (ca. $1000 \mathrm{~m} 2 \mathrm{~g}-1$ ).48 Water-sorption studies revealed similar behaviour, with a maximum water uptake of 0.27 gwater g-1 at an acetic acid concentration $30 \%$ (Fig. 4d). This value is slightly lower than that achieved for $\mathrm{Zr}$-fumarate synthesised under hydrothermal conditions and a reaction time of $16 \mathrm{~h}(0.36$ gwater g-1).55

\section{Multi-gram synthesis of UiO-66-NH2 beads}

We next demonstrated the scalability of this aqueous synthesis by fabricating UiO-66-NH2 beads on the multigram-scale (40 g; Fig S21, ESI †). To this end, we employed the optimised conditions described above. Thus, $792 \mathrm{~mL}$ of a $0.2 \mathrm{M}$ equimolar mixture of $\mathrm{ZrOCl} 2 \cdot 8 \mathrm{H} 2 \mathrm{O}$ and $\mathrm{BDC}-\mathrm{NH} 2$ in acetic acid in water $(30 \% \mathrm{v} / \mathrm{v})$ were injected into the coil-flow reactor $\left(\mathrm{Tc}: 90^{\circ} \mathrm{C}\right)$ at a liquid-feed rate (Qlf) of $2.4 \mathrm{~mL}$ min-1, and then spray-dried at a flow rate (Qdg) of $336 \mathrm{~mL}$ min-1 and an inlet temperature (Tin) of $150^{\circ} \mathrm{C}$ for $5.5 \mathrm{~h}$. After washing and drying, the resulting UiO-66-NH2 beads (40 g; yield: 85\%; Fig S22, ESI†) showed an SBET value of $1270 \mathrm{~m} 2 \mathrm{~g}-1$ and a total water uptake of 0.49 gwater g-1 (Fig. S23,24, ESI†). These values are similar to those obtained in the milligramscale synthesis. Additionally, we confirmed the long-term stability of the fabricated beads by comparing the XRPD patterns and $S_{\mathrm{BET}}$ values of a freshly prepared sample and a 1-year-old sample. We did not observe any significant differences between the two samples (Fig. S25, ESI $†$ ). 
This is the accepted version of the article: Avci-Camur, C., Troyano, J., Pérez-Carvajal, J., Legrand, A., Farrusseng, D., Imaz, I., Maspoch, D. Aqueous production of spherical Zr-MOF beads: Via continuous-flow spray-drying, Green Chemistry, 20(4):2018, p. 873-878. Available at: https:// doi.org/10.1039/c7gc03132g. All rights reserved

a)

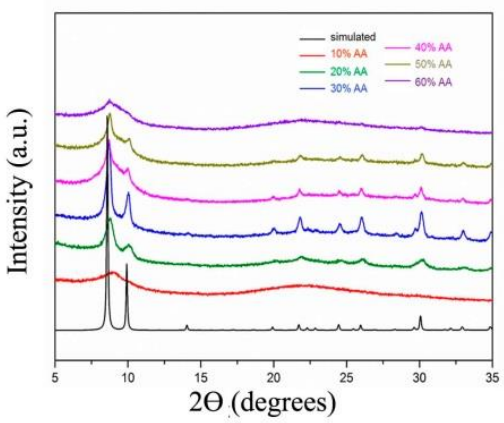

b)

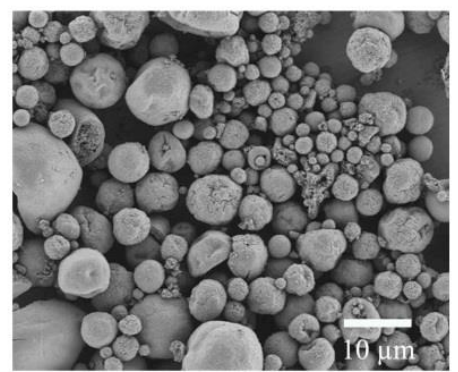

c)
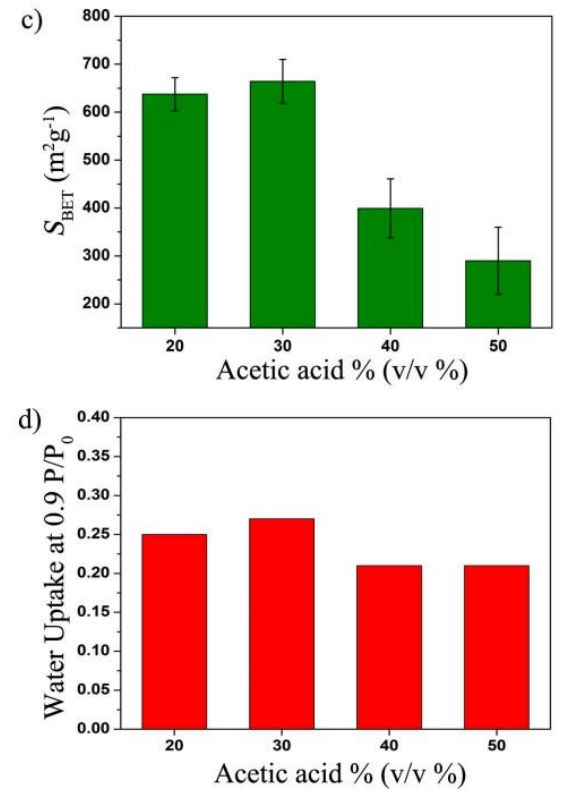

Figure 4. (a) XRPD diffractograms of Zr-fumarate synthesised using different amounts of acetic acid compared to the simulated powder pattern for Zr-fumarate (black). (b) Representative FESEM images of Zr-fumarate beads synthesised using a 30\% of acetic acid. (c,d) SBET values (c) and maximum water uptakes (d) of Zr-fumarate samples prepared using different amounts of acetic acid. 
This is the accepted version of the article: Avci-Camur, C., Troyano, J., Pérez-Carvajal, J., Legrand, A., Farrusseng, D., Imaz, I., Maspoch, D. Aqueous production of spherical Zr-MOF beads: Via continuous-flow spray-drying, Green Chemistry, 20(4):2018, p. 873-878. Available at: https:// doi.org/10.1039/c7gc03132g. All rights reserved

\section{CONCLUSIONS}

We have reported a continuous-flow spray-drying method for aqueous production of two representative Zr-MOFs: UiO-66-NH2 and Zr-fumarate. For both Zr-MOFs, a modulator (acetic acid) concentration of $30 \%(\mathrm{v} / \mathrm{v}$ in water) was found to be optimum, as it yielded microbeads whose SBET and water-uptake values were comparable to literature values obtained using other methods. In addition, our method obviates post-synthetic shaping methods, which usually reduce the porosity of MOFs. Lastly, as proof-of-concept on the scalability of our spray-drying approach, we used it to fabricate several grams of UiO-66-NH2 beads. Thus, this work opens the possibility of using spray-drying, a mature process already integrated in many industrial sectors, as a green method for the continuous one-step fabrication of shaped MOF microbeads.

\section{EXPERIMENTAL SECTION}

\section{Materials and methods}

Zirconium oxychloride octahydrate, 2-aminoterephthalic acid, fumaric acid and acetic acid were purchased from Sigma-Aldrich. All reagents were used without further purification. All reactions were performed using deionised water, obtained from a Milli-Q system (18.2 M $\Omega \mathrm{cm})$.

X-ray powder diffraction patterns were collected on an X'Pert PRO MPDP analytical diffractometer (Panalytical) at $40 \mathrm{kV}$ and $40 \mathrm{~mA}$ using $\mathrm{CuK} \alpha$ radiation $(\lambda=1.5419 \AA \AA)$. Nitrogen adsorption and desorption measurements were performed at $77 \mathrm{~K}$ using an Autosorb-IQ-AG analyser (Quantachrome Instruments). Specific surface area (SBET) was determined by applying the BET equation to the adequate region of the nitrogen isotherms. Pore volume was determined from the adsorbed volume at P/P0 0.3 of each isotherm. Prior to the measurements, samples were 
This is the accepted version of the article: Avci-Camur, C., Troyano, J., Pérez-Carvajal, J., Legrand, A., Farrusseng, D., Imaz, I., Maspoch, D. Aqueous production of spherical Zr-MOF beads: Via continuous-flow spray-drying, Green Chemistry, 20(4):2018, p. 873-878. Available at: https:// doi.org/10.1039/c7gc03132g. All rights reserved

degassed inside the cell under primary vacuum at $200{ }^{\circ} \mathrm{C}$ for $6 \mathrm{~h}(\mathrm{UiO}-66-\mathrm{NH} 2)$ or at $150{ }^{\circ} \mathrm{C}$ for $12 \mathrm{~h}$ (Zr-fumarate). Gravimetric water vapour-sorption isotherms were measured using a DVS vacuum instrument (Surface Measurement Systems Ltd). The weight of the dried powder $(\approx 20$ mg) was constantly monitored with a high-resolution microbalance $( \pm 0.1 \mu \mathrm{g})$ and recorded at 25 ${ }^{\circ} \mathrm{C}\left( \pm 0.2{ }^{\circ} \mathrm{C}\right)$ under pure water vapour pressures. Field-emission scanning electron microscopy (FESEM) images were collected on a FEI Magellan 400 L scanning electron microscope at an acceleration voltage of $2.0 \mathrm{kV}$, and on a FEI Quanta 650F scanning electron microscope at an acceleration voltage of $20.0 \mathrm{KV}$, using aluminium as a support. The degree of insertion of acetate inside the UiO-66-NH2 and Zr-fumarate frameworks was analysed by first digesting the samples, and then studying the resulting solutions by $1 \mathrm{H}-\mathrm{NMR}$. For UiO-66-NH2, the acetate/BDC-NH2 molar ratio was calculated by comparison of the integration of doublet at $7.75 \mathrm{ppm}$ corresponding to NH2-BDC and singlet at $1.9 \mathrm{ppm}$ corresponding to acetate. In the case of Zr-fumarate, the acetate/fumarate molar ratio was calculated by comparison of the integration of a singlet at 6.64 ppm corresponding to fumarate and a singlet at $1.9 \mathrm{ppm}$ corresponding to acetate. $1 \mathrm{H}-\mathrm{NMR}$ spectra of were collected on a Bruker AVANCE III $400 \mathrm{MHz}$ spectrometer. Thermogravimetric analyses were performed on a Perkin Elmer TGA 8000 Thermogravimetric analyser. A heating rate of 10 ${ }^{\circ} \mathrm{C}$ min-1 was used from room temperature up to $700{ }^{\circ} \mathrm{C}$.

\section{Optimised aqueous synthesis of UiO-66-NH2 by continuous-flow spray-drying}

$\mathrm{ZrOCl} 2 \cdot 8 \mathrm{H} 2 \mathrm{O}(773 \mathrm{mg}, 2.4 \mathrm{mmol})$ and 2-aminoterephthalic acid (435 mg, $2.4 \mathrm{mmol})$ were mixed under stirring in $12 \mathrm{~mL}$ of a $30 \%(\mathrm{v} / \mathrm{v})$ solution of acetic acid in water. The resulting mixture was injected, with agitation maintained, into a coil-flow reactor (Pyrex; $3 \mathrm{~mm}$, inner diameter) at a feed 
This is the accepted version of the article: Avci-Camur, C., Troyano, J., Pérez-Carvajal, J., Legrand, A., Farrusseng, D., Imaz, I., Maspoch, D. Aqueous production of spherical Zr-MOF beads: Via continuous-flow spray-drying, Green Chemistry, 20(4):2018, p. 873-878. Available at: https:// doi.org/10.1039/c7gc03132g. All rights reserved

rate (Qlf) of $2.4 \mathrm{~mL}$ min-1 and a bath temperature (Tc) of $90^{\circ} \mathrm{C}$. The pre-heated yellow slurry was then spray-dried at a flow rate (Qdg) of $336 \mathrm{~mL}$ min-1 (spray-cap hole diameter: $0.5 \mathrm{~mm}$ ) and an inlet temperature (Tin) of $150{ }^{\circ} \mathrm{C}$, using a B-290 Mini Spray Dryer (BUCHI Labortechnik). The resulting yellow powder was collected, dispersed in ethanol at room temperature, precipitated by centrifugation three times, left to stand in ethanol overnight, and washed twice with acetone. The solid was dried for $12 \mathrm{~h}$ at $75^{\circ} \mathrm{C}$ in a conventional oven to afford the final product (yield: $64 \%$ ).

\section{Optimised aqueous synthesis of Zr-fumarate by continuous-flow spray-drying}

$\mathrm{ZrOCl} 2 \cdot 8 \mathrm{H} 2 \mathrm{O}(644 \mathrm{mg}, 2.0 \mathrm{mmol})$ and fumaric acid $(232 \mathrm{mg}, 2.0 \mathrm{mmol})$ were mixed under stirring in $10 \mathrm{~mL}$ of a $30 \%(\mathrm{v} / \mathrm{v})$ solution of acetic acid in water. The resulting mixture was injected into a coil-flow reactor (Pyrex; $3 \mathrm{~mm}$, inner diameter), with agitation maintained, at a feed rate of $2.4 \mathrm{~mL}$ min-1 and bath temperature $(\mathrm{Tc})$ of $90^{\circ} \mathrm{C}$. The resulting white slurry was spray-dried at a flow rate Qdg of $336 \mathrm{~mL}$ min-1 and an inlet temperature (Tin) of $140{ }^{\circ} \mathrm{C}$. The resulting white powder was collected, dispersed in water at room temperature, left to stand overnight, and precipitated by centrifugation twice. This process was then repeated with ethanol instead of water. The solid was dried for $12 \mathrm{~h}$ at $75^{\circ} \mathrm{C}$ in a conventional oven to afford the final product (yield: $58 \%)$.

\section{ACKNOWLEDGEMENTS}

This work was supported by the Spanish MINECO (projects PN MAT2015-65354-C2-1-R), the Catalan AGAUR (project 2014 SGR 80), the ERC under the EU-FP7 (ERC-Co 615954), and the EU Horizon 2020 research and innovation programme PRODIA (grant agreement \#685727). It 
This is the accepted version of the article: Avci-Camur, C., Troyano, J., Pérez-Carvajal, J., Legrand, A., Farrusseng, D., Imaz, I., Maspoch, D. Aqueous production of spherical Zr-MOF beads: Via continuous-flow spray-drying, Green Chemistry, 20(4):2018, p. 873-878. Available at: https:// doi.org/10.1039/c7gc03132g. All rights reserved

was also funded by the CERCA Programme/Generalitat de Catalunya. ICN2 acknowledges the support of the Spanish MINECO through the Severo Ochoa Centres of Excellence Programme, under Grant SEV-2013-0295.

\section{REFERENCES}

1. A. D. Wiersum, E. Soubeyrand-Lenoir, Q. Yang, B. Moulin, V. Guillerm, M. B. Yahia, S. Bourrelly, A. Vimont, S. Miller, C. Vagner, M. Daturi, G. Clet, C. Serre, G. Maurin and P. L. Llewellyn, Chem. Asian J., 2011, 6, 3270-3280.

2. J. A. Mason, M. Veenstra and J. R. Long, Chem. Sci., 2014, 5, 32-51.

3. J. Yu, L.-H. Xie, J.-R. Li, Y. Ma, J. M. Seminario and P. B. Balbuena, Chem. Rev., 2017, 117, 9674-9754.

4. F. G. Cirujano, A. Leyva-Pérez, A. Corma and F. X. Llabrés i Xamena, ChemCatChem, 2013, $5,538-549$.

5. J. Lee, O. K. Farha, J. Roberts, K. A. Scheidt, S. T. Nguyen and J. T. Hupp, Chem. Soc. Rev., 2009, 38, 1450-1459.

6. F. Jeremias, D. Fröhlich, C. Janiak and S. K. Henninger, New J. Chem., 2014, 38, 1846-1852.

7. S. K. Henninger, F. Jeremias, H. Kummer and C. Janiak, Eur. J. Inorg. Chem., 2012, 2012, 2625-2634.

8. M. F. de Lange, B. L. van Velzen, C. P. Ottevanger, K. J. F. M. Verouden, L.-C. Lin, T. J. H. Vlugt, J. Gascon and F. Kapteijn, Langmuir, 2015, 31, 12783-12796.

9. M. F. de Lange, K. J. F. M. Verouden, T. J. H. Vlugt, J. Gascon and F. Kapteijn, Chem. Rev., 2015, 115, 12205-12250.

10. A. V. Desai, B. Manna, A. Karmakar, A. Sahu and S. K. Ghosh, Angew. Chem., Int. Ed., 2016, $55,7811-7815$.

11. R. Ricco, K. Konstas, M. J. Styles, J. J. Richardson, R. Babarao, K. Suzuki, P. Scopece and P. Falcaro, J. Mater. Chem. A, 2015, 3, 19822-19831.

12. P. A. Julien, C. Mottillo and T. Friscic, Green Chem., 2017, 19, 2729-2747.

13. H. Reinsch, B. Bueken, F. Vermoortele, I. Stassen, A. Lieb, K.-P. Lillerud and D. De Vos, CrystEngComm, 2015, 17, 4070-4074.

14. H. Reinsch, Eur. J. Inorg. Chem., 2016, 27, 4290-4299.

15. M. Rubio-Martinez, C. Avci-Camur, A. W. Thornton, I. Imaz, D. Maspoch and M. R. Hill, Chem. Soc. Rev., 2017, 46, 3453-3480. 
This is the accepted version of the article: Avci-Camur, C., Troyano, J., Pérez-Carvajal, J., Legrand, A., Farrusseng, D., Imaz, I., Maspoch, D. Aqueous production of spherical Zr-MOF beads: Via continuous-flow spray-drying, Green Chemistry, 20(4):2018, p. 873-878. Available at: https:// doi.org/10.1039/c7gc03132g. All rights reserved

16. H. Reinsch and N. Stock, Dalton Trans., 2017, 46, 8339-8349.

17. M. Taddei, Coord. Chem. Rev., 2017, 343, 1-24.

18. H. Wu, Y. S. Chua, V. Krungleviciute, M. Tyagi, P. Chen, T. Yildirim and W. Zhou, JACS, 2013, 135, 10525-10532.

19. A. W. Thornton, R. Babarao, A. Jain, F. Trousselet and F. X. Coudert, Dalton Trans., 2016, $45,4352-4359$.

20. N. C. Burtch, H. Jasuja and K. S. Walton, Chem. Rev., 2014, 114, 10575-10612.

21. B. S. Gelfand and G. K. H. Shimizu, Dalton Trans., 2016, 45, 3668-3678.

22.Y.-H. Shih, Y.-C. Kuo, S. Lirio, K.-Y. Wang, C.-H. Lin and H.-Y. Huang, Chem. Eur. J., 2017, $23,42-46$.

23. P. A. Bayliss, I. A. Ibarra, E. Perez, S. Yang, C. C. Tang, M. Poliakoff and M. Schroder, Green Chem., 2014, 16, 3796-3802.

24. T. Didriksen, A. I. Spjelkavik and R. Blom, J. Flow Chem., 2017, 7, 13-17.

25. H. Reinsch, S. Waitschat, S. M. Chavan, K. P. Lillerud and N. Stock, Eur. J. Inorg. Chem., 2016, 27, 4490-4498.

26. A. S. Munn, P. W. Dunne, S. V. Y. Tang and E. H. Lester, Chem. Commun., 2015, 51, 1281112814.

27. A. Garcia Marquez, P. Horcajada, D. Grosso, G. Ferey, C. Serre, C. Sanchez and C. Boissiere, Chem. Commun., 2013, 49, 3848-3850.

28. A. Carné-Sánchez, I. Imaz, M. Cano-Sarabia and D. Maspoch, Nat. Chem., 2013, 5, 203-211.

29. L. Garzon-Tovar, M. Cano-Sarabia, A. Carne-Sanchez, C. Carbonell, I. Imaz and D. Maspoch, React. Chem. Eng., 2016, 1, 533-539.

30. V. Guillerm, L. Garzon-Tóvar, A. Yazdi, I. Imaz, J. Juanhuix and D. Maspoch, Chem. Eur. J., 2017, 23, 6829-6835.

31. L. Garzón-Tovar, J. Pérez-Carvajal, I. Imaz and D. Maspoch, Adv. Funct. Mater., 2017, 27, 1606424.

32. T. H. Kim and S. G. Kim, Saf. Health Work, 2011, 2, 97-104.

33. K.-W. Kim and Y. H. Chung, Toxicol. Res., 2013, 29, 187-193.

34. K. C. A. Bromley-Challenor, N. Caggiano and J. S. Knapp, J. Ind. Microbiol. Biotechnol., 2000, 25, 8-16.

35. C. A. Redlich, W. S. Beckett, J. Sparer and et al., Ann. Intern. Med., 1988, 108, 680-686. 
This is the accepted version of the article: Avci-Camur, C., Troyano, J., Pérez-Carvajal, J., Legrand, A., Farrusseng, D., Imaz, I., Maspoch, D. Aqueous production of spherical Zr-MOF beads: Via continuous-flow spray-drying, Green Chemistry, 20(4):2018, p. 873-878. Available at: https:// doi.org/10.1039/c7gc03132g. All rights reserved

36. J. H. Cavka, S. Jakobsen, U. Olsbye, N. Guillou, C. Lamberti, S. Bordiga and K. P. Lillerud, JACS, 2008, 130, 13850-13851.

37. X. Liu, N. K. Demir, Z. Wu and K. Li, JACS, 2015, 137, 6999-7002.

38. H. Kim, S. Yang, S. R. Rao, S. Narayanan, E. A. Kapustin, H. Furukawa, A. S. Umans, O. M. Yaghi and E. N. Wang, Science, 2017, 356, 430-434.

39. G. C. Shearer, S. Chavan, S. Bordiga, S. Svelle, U. Olsbye and K. P. Lillerud, Chem. Mater., 2016, 28, 3749-3761.

40. T. Tian, J. Velazquez-Garcia, T. D. Bennett and D. Fairen-Jimenez, J. Mater. Chem. A, 2015, 3, 2999-3005.

41. J. Dhainaut, C. Avci-Camur, J. Troyano, A. Legrand, J. Canivet, I. Imaz, D. Maspoch, H. Reinsch and D. Farrusseng, CrystEngComm, 2017, 19, 4211-4218.

42. D. Crawford, J. Casaban, R. Haydon, N. Giri, T. McNally and S. L. James, Chem. Sci., 2015, $6,1645-1649$.

43. I. Stassen, M. Styles, T. Van Assche, N. Campagnol, J. Fransaer, J. Denayer, J.-C. Tan, P. Falcaro, D. De Vos and R. Ameloot, Chem. Mater., 2015, 27, 1801-1807.

44.P. M. Schoenecker, G. A. Belancik, B. E. Grabicka and K. S. Walton, AlChE J., 2013, 59, 1255-1262.

45. O. G. Nik, X. Y. Chen and S. Kaliaguine, J. Membr. Sci., 2012, 413, 48-61.

46. S. Diring, S. Furukawa, Y. Takashima, T. Tsuruoka and S. Kitagawa, Chem. Mater., 2010, 22, 4531-4538.

47. T. Tsuruoka, S. Furukawa, Y. Takashima, K. Yoshida, S. Isoda and S. Kitagawa, Angew. Chem. Int. Ed., 2009, 121, 4833-4837.

48. H. Reinsch, S. Waitschat, S. M. Chavan, K. P. Lillerud and N. Stock, Eur. J. Inorg. Chem., 2016, 27, 4490-4498.

49. S. Waitschat, H. Reinsch and N. Stock, Chem. Commun., 2016, 52, 12698-12701.

50. Z. Hu, I. Castano, S. Wang, Y. Wang, Y. Peng, Y. Qian, C. Chi, X. Wang and D. Zhao, Cryst. Growth Des., 2016, 16, 2295-2301.

51. M. R. DeStefano, T. Islamoglu, S. J. Garibay, J. T. Hupp and O. K. Farha, Chem. Mater., 2017, $29,1357-1361$.

52. F. Jeremias, V. Lozan, S. K. Henninger and C. Janiak, Dalton Trans., 2013, 42, 15967-15973.

53. J. Canivet, J. Bonnefoy, C. Daniel, A. Legrand, B. Coasne and D. Farrusseng, New J. Chem., 2014, 38, 3102-3111. 
This is the accepted version of the article: Avci-Camur, C., Troyano, J., Pérez-Carvajal, J., Legrand, A., Farrusseng, D., Imaz, I., Maspoch, D. Aqueous production of spherical Zr-MOF beads: Via continuous-flow spray-drying, Green Chemistry, 20(4):2018, p. 873-878. Available at: https:// doi.org/10.1039/c7gc03132g. All rights reserved

54. J. Ren, N. M. Musyoka, H. W. Langmi, B. C. North, M. Mathe, X. Kang and S. Liao, Int. J. Hydrog. Energy, 2015, 40, 10542-10546.

55. Y. J. Bae, E. S. Cho, F. Qiu, D. T. Sun, T. E. Williams, J. J. Urban and W. L. Queen, ACS Appl. Mater. Inter., 2016, 8, 10098-10103. 